\title{
Rare Solitary Naevus Lipomatosis Cutaneous Superficialis: Histopathology A Diagnostic Clue
}

\section{Thapa DP ${ }^{1}$, Singh $\mathbf{M}^{2}$}

${ }^{1}$ Associate Professor, Nepal Medical College and Teaching Hospital, Kathmandu, Nepal; ${ }^{2}$ Registrar, Nepal Cancer Hospital and Research Centre, Kathmandu, Nepal

\begin{abstract}
Key words: Adipocytes; Hamartoma; Lipomatosis

\section{Introduction}

$\mathrm{N}$ aevus lipomatosis cutaneous superficialis (NCLS) is a rare form of hamartoma characterized by presence of mature adipocytes in dermis. Clinically it presents in two forms namely, the classical HoffmannZuhellie form characterize by multiple, soft non tender, pedunculated, yellowish or skin colored, nodules or plaques of varying sizes. In the solitary form, characterized by a solitary, pedunculated, flesh colored papule or nodule. ${ }^{1}$
\end{abstract}

We present a case of 45 year old female, presenting with a solitary, asymptomatic, pedunculated mass since childhood. The lesion was totally excised and was sent for histopathological evaluation and was found to be Naevus lipomatosis cutaneous superficialis which is a rare form of hamartoma in which mature adipocytes are found in the dermis.

\section{Case report}

A 45 year female presented to our outpatient department (OPD) with a solitary pedunculated mass near groin since childhood. It was asymptomatic. Her concern of being a cancer brought her to our OPD. On examination, the mass was yellowish to skin colored, pedunculated, soft in consistency with cerebriform surface measuring about $9 \mathrm{~cm} \times 5 \mathrm{~cm}$ over left lower quadrant of abdomen near groin as shown in Figure 1. There were no cafe au lait macules, axillary freckling or any other skin lesions in other parts of the body including palms and soles. Scalp, nails and mucous membranes were normal. Systemic examination was normal. The lesion was totally excised and was sent for histopathological examination,with differential

Funding: No

Conflict of Interest: No

\section{Address of Correspondence}

Dr. Deeptara Pathak Thapa

Associate professor, Department of Dermatology, Nepal Medical College and teaching Hospital, Kathmandu, Nepal Phone: 00977-4911008

E-mail: drdeeptarapathak@yahoo.com diagnosis of neurofiroma, Lipoma, giant achrochordon, and Nevus lipomatous cutaneous superficialis.The gross section of the lesion is shown in Figure 2 . In histopathology there were presence of adipocytes in dermis which was consistent with diagnosis of Naevus lipomatosis cutaneous superficialis as shown in Figure 3 and Figure 4.

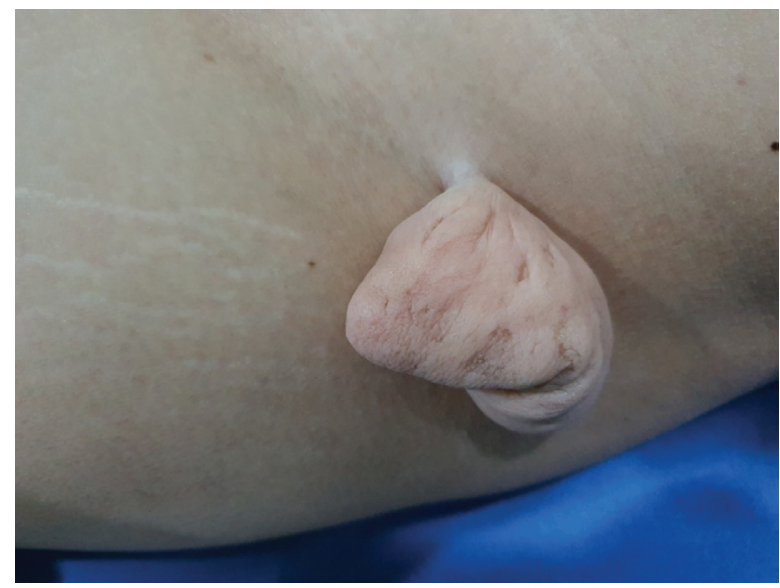

Figure 1: Pedunculated mass of yellowish to skin colored on left lower quadrant near left groin

Submitted: $4^{\text {th }}$ January 2021

Accepted: $6^{\text {th }}$ February 2021

Published: $20^{\text {th }}$ February 2021

How to cite this article

Thapa DP, Singh M. Rare Solitary Naevus Lipomatosis Cutaneous Superficialis: Histopathology A Diagnostic Clue. Nepal Journal of Dermatology, Venereology \& Leprology 2021;19(1):68-70. https://doi.org/10.3126/njdvl.v19i1.35412.

\section{(c) (i)}

Licensed under CC BY 4.0 International License which permits use, distribution and reproduction in any medium, provided the original work is properly cited. 


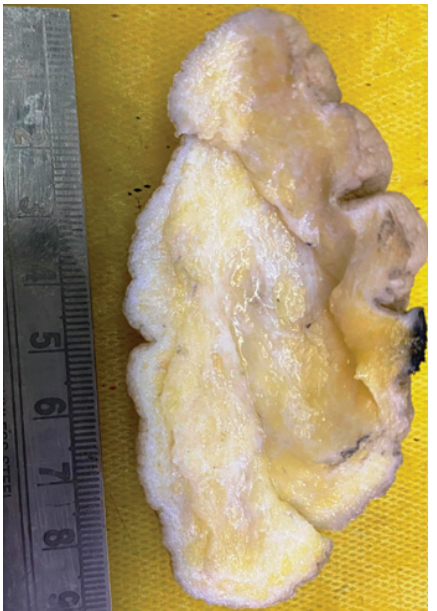

Figure 2: Cut section of the lesion shows yellowish fatty appearance extending to deeper planes.

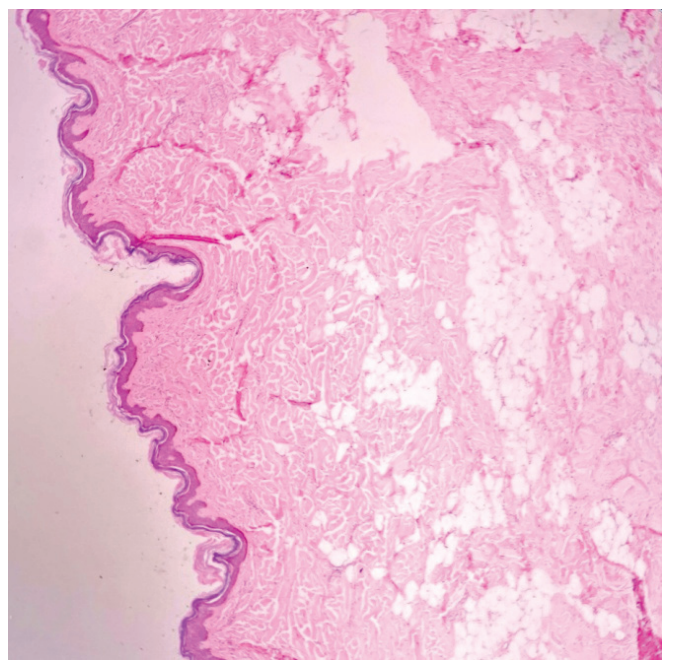

Figure 3: Photomicrograph showing unencapsulated lesion comprising of mature adipose tissue within the superficial dermis.(H\&E 100X)

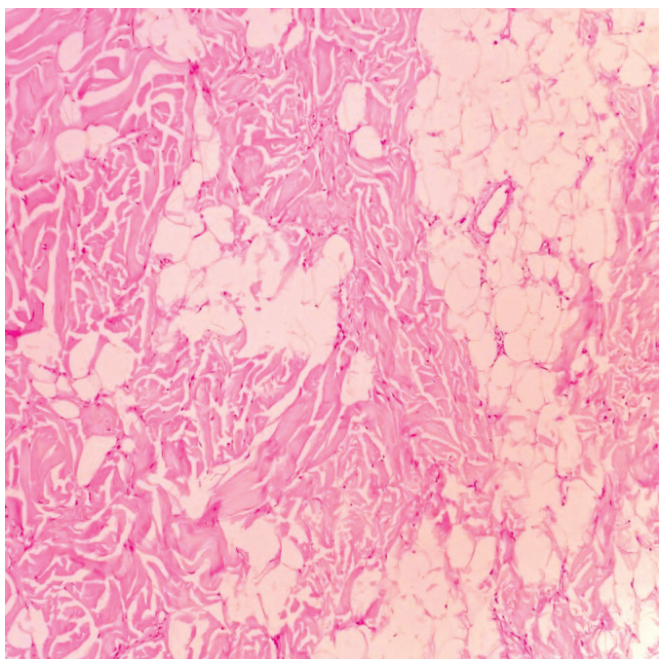

Figure 4: Photomicrograph shows lobules of mature adipose tissue infiltrating the dermal collagen. (H\& E 100X)

\section{Discussion}

Naevus lipomatosis cutaneous superficialis was first coined by Hoffman and Zuhelle in $1921 .^{2}$ There is no familial or sex predilection. ${ }^{1}$ Clinical presentation of the classical lesions are usually present at birth or in the first two to three decades of life in a zonal or segmental distribution over the buttocks, lower back or upper thighs whereas solitary types develop in adults and show a wider distribution in the skin.The nodules can be pedunculated or sessile with smooth or wrinkled surface sometimes may be hairy or show comedo like plugs. The solitary clinical form of NLCS presented as a solitary papule or nodule mimicking a skin tag which usually appears during the third to sixth decades of life and can occur anywhere on the skin. ${ }^{1,3}$

Rarely solitary types can also occur in sites like the scalp, eyelids, nose and clitoris. ${ }^{4}$

Histopathological features are similar in both clinical presentation with varying degree of adipose tissue ( $10 \%$ to $50 \%$ ) embedded between collagen bundles of the dermis. ${ }^{5,6}$

The etiopathogenesis of NLCS is still unknown. As proposed by Hoffman and Zurhelle that it is the degenerative changes in the dermal collagen and elastic tissue which leads to the deposition of adipose tissue in the dermis. ${ }^{7}$

Another hypothesis states that adipose metaplasia of dermal connective tissue or representation of a true nevus occurs from focal heterotropic development during embryonic life. Recently deletion of 2 p24 in the NLCS has been reported. ${ }^{8}$ surgical excision is the treatment of choice. Psychological concern related to be of cancerous origin from patient point of view and confirming with histopathological examination is a very important diagnostic tool to have clinicohistopathological correlation for treating physician and proper counseling for affected patients. We present this case for its rarity and till date not yet been reported from this part of the world. 


\section{References}

1. Lima CDS, Issa MCA,Souza MBD, Goes HFO, Santos TBP, Vilar EAG. Nevus lipomatosus cutaneous superficialis. An Bras Dermatol 2017; 92: 711-3. https://doi.org/10.1590/abd18064841.20175217

2. Dotz W, Prioleau PG. Nevus lipomatosus cutaneous superficialis. Arch Dermatol 1984;120:376-9. https://doi. org/10.1001/archderm.1984.01650390098021

3. Dhamija A, Meherda A, D'Souza P, Meena RS. Nevus lipomatosus cutaneous superficialis: An unusual presentation. Indian Dermatol Online J 2012;3:196-8. https://doi.org/10.4103/22295178.101819

4. Patil SB, Narchal S, Paricharak M, More SS. Nevus lipomatosus cutaneous superficialis: a rare case report. Iran J Med Sci 2014;39(3):304-7.
5. Ranjkesh MR, Herizchi QH, Yousefi N. Nevus Lipomatosus Cutaneous Superficialis: A Case Report with Histological Findings. J Turk Acad Dermatol 2009;3:93103c.

6. Bairwa S, Sharma M, Sangwaiya A, Singla S, Gupta K, Yadav A. Nevus lipomatosus cutaneous superficialis with unusual presentation over the nipple. Indian J Dermatol 2017;62:429-31. https://doi.org/10.4103/ijd.IJD_384_16

7. Khandpur S, Nagpal SA, Chandra S, Sharma VK, Kaushal S, Safaya R. Giant nevus lipomatosus cutaneous superficialis. Indian J Dermatol Venereol Leprol 2009;75:407-8. https://doi. org/10.4103/0378-6323.53149.

8. Cardot-Leccia N, Italiano A, Monteil MC, Basc E, Perrin C, Pedeutour F. Naevus lipomatosus superficialis: A case report with a 2p24 deletion. $\mathrm{Br} J$ Dermatol 2007;156:380-1. https://doi. org/10.1111/j.1365-2133.2006.07622.x 